\title{
蹘Irestice
}

\section{Tecnologias educacionais digitais na formação de preceptores para residências multiprofissionais no SUS}

\author{
Digital educational technologies in the formation of preceptors for multiprofessional \\ residences in SUS
}

Emanuelly Mota Silva Rodrigues ${ }^{1}$, Karla Kristine Dames da Silva ${ }^{2}$

\begin{abstract}
Resumo
Introdução: Os Programas de Residências Multiprofissionais em Saúde são pós-graduações lato-sensu, caracterizando-se como ensino em serviço. Fazem parte do programa de educação permanente, formando assim novos profissionais de saúde para o SUS. Objetivo: esse trabalho objetiva expor a experiência de reflexão e construção de uma proposta de formação de preceptores para os programas de residência, através do uso de tecnologias educacionais digitais e metodologias ativas de ensino-aprendizagem, com o objetivo de iniciar um processo de educação continuada junto a esses profissionais. Método: Foram elencados artigos científicos e documentais para embasar a importância de trabalhar a formação docente desses preceptores. Em seguida, foram pensadas temáticas importantes para a iniciação da formação, bem como para sua estruturação. Resultado: o produto desse relato é uma análise sobre a formação de preceptores, gerando subsídios para educação continuada, bem como dos recursos tecnológicos de avaliação desse processo pedagógico. Conclusão: Assim, concluímos que a formação pedagógica para preceptores de residências fortalece os programas e consequentemente a especialização de novos profissionais para 0 SUS.
\end{abstract}

Palavras-Chave: Residências multiprofissionais; Preceptoria; Tecnologia educacional.

\begin{abstract}
Introduction: The Multiprofessional Health Residency Programs are lato-sensu postgraduate programs, characterized by in-service teaching. It is part of the continuing education program, training new health professionals for SUS. Objective: This paper aims to expose an experience of reflection and construction of a proposal for training preceptors for residency programs, using the use of digital educational technologies and learning teaching methods, with the objective of initiating a continuous education process together. to these professionals. Method: Scientific articles and documents were listed to support the importance of working with the teacher education of these preceptors. Then, they were thought of important themes for the beginning of this formation, as well as its structuring. Result: the product of this kind of
\end{abstract}

\footnotetext{
1 Especialista. Centro Regional Integrado de Oncologia - CRIO. Email: manuhmota@hotmail.com 2 Doutora. Fundação Oswaldo Cruz - FIOCRUZ. Email: kkdames@gmail.com

Correspondência: Rua Francisco Calaça, 1300. Bairro Álvaro Weyne. Fortaleza - Ceará.
} 
relationship is a formation of preceptors, generating subsidies for a further continuing education, as well as technological resources to evaluate this pedagogical process. Conclusion: Thus, it is concluded that a pedagogical training for preceptors of residence strengthens the programs and consequently a specialization of new professionals for SUS.

Keywords: Multiprofessional residency; Preceptorship; Educational technology

\section{Introdução}

A saúde é um direito garantido e fundamental, sendo o "completo bem-estar físico, mental e social, não consistindo apenas na ausência de doença ou enfermidade" 1.

Para garantir a promoção e cuidado em saúde de forma eficaz, existe a Política de Educação Permanente, instituída através da Portaria n¹98/GM de 13 de fevereiro de 2014, como estratégia para a formação baseando-se na aprendizagem significativa e na possibilidade de transformar as práticas dos trabalhadores da saúde que visam garantir a formação e desenvolvimento dos trabalhadores do SUS. Promover esse espaço é facilitar um cuidado adequado, já que profissionais bem capacitados atendem melhor os usuários ${ }^{2}$.

Sendo o SUS uma escola, é importante refletir sobre a potencialidade da sua capacidade pedagógica, tendo a educação permanente de seus profissionais como processo contínuo e inacabado. É destacado também sua importância para o desenvolvimento de serviços de saúde críticos, reflexivos, propositivos e tecnicamente competentes ${ }^{3}$.
Entretanto, é evidenciada a importância dessa educação permanente para a perpetuação da justiça social, refletindo sobre a baixa articulação da formação base de profissionais de saúde, sobretudo de nível médio, para as reais necessidades do território. Assim, recai sobre os serviços de saúde o ônus de prover educação voltada para o contexto social. As autoras destacam também a dificuldade em realizar promoção de saúde quando faltam ações como saneamento básico ${ }^{4}$.

A Residência Multiprofissional em Saúde está inclusa nesse programa, sendo uma pós-graduação lato sensu na estrutura de ensino em serviço, isso é, diferente da pós-graduação convencional, as principais salas de aulas na residência são os próprios serviços de saúde. Visando capacitar e especializar profissionais de saúde para atuação humanizada, capaz e perita desses trabalhadores com, para e no SUS, incentiva-se a educação popular em saúde, práticas integrativas e ações que promovam a autonomia e autocuidado do usuário. Esses programas se constituem em uma formação "no" e "pelo trabalho", tendo os serviços de saúde como cenários 
de aprendizado e prática, dispondo dos preceptores como principais docentes e sendo regidos pelos Projetos PolíticoPedagógicos com a regência da Comissão Nacional de Residências em Saúde $\mathrm{CNRMS}^{5}$.

Ao ingressar em um programa de residência, o profissional de saúderesidente assume uma carga horária de 60 horas semanais em regime de dedicação exclusiva. A exaustão da longa jornada de trabalho, em muitas vezes, é um fator de adoecimento. Nesse contexto encontra-se o preceptor, aquele que acompanha o residente em $80 \%$ da sua formação.

A atual distribuição dessa carga horária conta com $80 \%$ dedicados às atividades práticas e teórico-práticas e $20 \%$ teórico-conceituais. Este intenso contato com o cenário de prática favorece a compreensão não apenas do processo saúde-doença, mas do contexto social, político e econômico em que a rede de saúde está inserida. Muitas vezes o grande professor é o próprio usuário, e reconhecer isso é destaque na formação profissional.

Contextualizando historicamente, os programas de residência no país iniciaramse através das residências médicas, por meio do Decreto $n^{\circ} 80.281$, de 05 de setembro de 1977. Foi constituída a Comissão Nacional de Residência Médica (CNRM), responsável por estabelecer princípios e normas de funcionamento, avaliação e credenciamento dos programas de residência médica. Esse decreto foi regulamentado enquanto lei em 1981, através da Lei n 6.932, como uma modalidade de pós-graduação destinada a médicos, caracterizada pelo treinamento em serviço, em regime de dedicação exclusiva, sob a orientação de profissionais de elevada qualificação ${ }^{6}$.

Apesar de existirem desde 1975, as residências multiprofissionais em área profissional de saúde somente foram regulamentadas em 2005, por meio da Lei $n^{\circ} 11.129$, com a perspectiva de uma clínica ampliada em saúde, obedecendo aos mesmos critérios da Residência Médica.

Atualmente as residências multiprofissionais, depois de submetidas e aprovadas, possuem financiamento de bolsas garantidas pelo Ministério da Saúde ou pelo Ministério da Educação, além de ser possível o financiamento próprio do município ou instituição de ensino. No entanto, a renumeração de preceptores não é garantida, sendo em sua grande maioria um acúmulo de função.

Partindo disso, assim como se preza por zelar do cuidador, também se faz necessário capacitar o profissional de saúde preceptor, responsável por conduzir o processo formativo em serviço. Para tal, se faz importante o uso das Tecnologias Digitais da Informação e das Comunicações (TDICs) ao nosso favor, utilizando recursos que ampliem as 
possibilidades de ensino. As tecnologias educacionais são recursos de suporte essenciais para a modernização do processo de ensino-aprendizagem, e a elas se recorre, entre outros motivos, para criar e recriar formas de interação entre usuário e profissional de saúde ${ }^{7}$.

A importância do uso das (TDICs) no contexto educacional acompanha a própria evolução tecnológica, sobretudo pelo crescimento da educação a distância, bem como da tecnologia em todos os contextos. Sendo assim, é importante destacar sua importância não apenas como recursos auxiliares, mas como elementos estruturantes no processo formativo. Se vivemos um tempo em que as tecnologias se aperfeiçoam continuamente, a educação tem como missão acompanhar os avanços tecnológicos, utilizando a seu favor todas as soluções possíveis. ${ }^{8}$.

Esse relato surge como uma proposta de intervenção para conclusão do curso de especialização em Tecnologias Educacionais para a Prática Docente do Ensino da Saúde na Escola, promovida pela Fundação Oswaldo Cruz - FIOCRUZ. Sua justificativa recai na importância de fundamentar seu uso para a formação de preceptores de residências, sendo essa uma dificuldade a nível nacional. Essas formações existem, mas não contemplam todos os preceptores e estados. A lacuna na formação docente adequada de preceptores compromete de forma significativa a condução dos programas de residência, logo esse fator influencia no egresso inserido posteriormente no SUS. A relevância está no fato de que o material aqui desenvolvido pode contribuir com outros programas, levando em conta que não é algo restrito, sendo passível para adaptações nas mais diversas realidades.

O objetivo é descrever uma proposta para a formação de preceptores na Residência Multiprofissional, através do uso de tecnologias educacionais empregando as TDICs para ensino em saúde no âmbito do SUS.

\section{Métodos}

A proposta em questão ocorreu em um centro oncológico na cidade de Fortaleza/CE, cenário de prática de uma residência multiprofissional em saúde com ênfase em cancerologia. Conta atualmente com 18 residentes nas especialidades: fisioterapia, psicologia, nutrição, enfermagem, serviço social e farmácia.

Propondo implementar o uso de tecnologias digitais e Metodologias Ativas de Ensino e Aprendizagem (MAEA) na condução da residência, foi elaborada uma proposta de formação para preceptorias no SUS, tendo como percurso inicialmente um levantamento bibliográfico sobre quais as competências necessárias para ser um preceptor. Posteriormente, foram montadas unidades de aprendizado 
baseadas nessas competências, onde aconteceram encontros presenciais utilizando metodologias ativas, facilitados por professores convidados e as autoras do presente relato. A formação aconteceu através de educação híbrida, sendo possível para subsidiar a carga horária a distância o uso de fóruns de discussão na plataforma Canvas para interação entre os alunos e suporte dos tutores.

Essa plataforma foi desenvolvida através do site "Canvas" de forma gratuita, onde foram inseridos além desses fóruns, vídeos no YouTube, um calendário com as datas dos encontros presenciais, atividades disparadoras referentes aos módulos, avaliação e monitoramento do curso, dentre outros recursos. O público alvo dessa intervenção foram 22 preceptores de núcleo (categoria profissional) e 2 de campo (cuidado transversal e SUS), sendo profissionais com grande expertise em oncologia, mas em sua maioria sem formação para a docência.

A formação contou com uma grade curricular baseada em competências, refletindo sobre quais habilidades se esperam que o preceptor tenha, utilizando de materiais didático-pedagógicos que facilitem o processo de aprendizado. Nessa construção não foram consideradas apenas competências pedagógicas, mas também as de facilitadores da promoção da saúde e autonomia dos usuários.
Encontramos como principais competências do preceptor para a atenção à saúde: (a) o conhecimento dos conteúdos e técnicas a serem ensinados torna-se essencial. Nesse viés estamos em vantagem, já que em sua maioria os preceptores são profissionais especialistas e com expertise na área de ensino; (b) tomada de decisões, com reformulações periódicas de condutas e ensino baseado nas limitações e especificidades de cada aluno; (c) comunicação, inclusive proporcionando meios de aprendizado a distância para desenvolver cooperação residentes-residentes e residentesprofissionais do serviço; (d) liderança, direcionando as ações em uma perspectiva longitudinal; (e) administração e gerenciamento, trabalhando a partir dos erros e dificuldades de aprendizagem; (f) educação permanente, estabelecendo seu próprio programa pessoal de desenvolvimento ${ }^{9}$.

Durante a realização, além das avaliações dos alunos, foram aplicadas avaliações de monitoramento do próprio curso, visando identificar pontos fortes e as melhorarias na busca de aperfeiçoamento. Essas avaliações foram aplicadas ao fim de cada módulo e seus dados compilados na tentativa de superar as dificuldades detectadas, de um módulo para outro, através da Plataforma Canvas.

As questões de monitoramento do curso contaram com os itens: 
- Na sua percepção, as temáticas apresentadas nesse módulo tinham relação com o seu cotidiano?

- Quais conhecimentos foram novidade?

- Você conhecia as tecnologias digitais utilizadas nesse módulo?

\section{Resultados}

Espera-se com essa formação contar com preceptores mais capacitados e motivados, entendendo o processo de formação da residência e sentindo-se pertencentes a essa construção contínua.

Para seu desenvolvimento, foi necessário pensar em quais os problemas que permeiam a nossa vivência prática. Com isso, foram percebidas algumas problemáticas, dentre elas a ausência de um programa de educação continuada para preceptores da residência. Um fator importante nesse planejamento é perceber a governabilidade na resolução do nó crítico, como por exemplo, se há disponibilidade dos recursos necessários para a resolução dessa questão.

Além da necessidade de uma formação focada no ensino, já que em sua maioria são profissionais de saúde preparados apenas para a assistência, essa capacitação é uma forma de valorização profissional tendo em vista ser nula, como citado anteriormente, a renumeração efetiva pela preceptoria, na maioria dos serviços de saúde. Assim, o aprimoramento do conhecimento e currículo seria um diferencial para o profissional. O curso contou com uma carga horária total de 100 horas, sendo certificado pelo Centro de Ensino e Pesquisa da instituição proponente, também financiadora da execução desse projeto.

Apesar do SUS ser em sua essência escola, a grande maioria dos profissionais de saúde não foram preparados para essa missão. Recebem para educação em serviço estagiários, aprendizes e residentes, no entanto possuem uma formação voltada para a assistência, não para a docência.

Para além do desafio da formação pedagógica falha, é preciso levar em conta a importância do aprendizado do uso de novas estratégias, como o empoderamento do estudante enquanto protagonista do seu aprendizado e o uso de tecnologias educacionais, trazendo ao nosso favor esses recursos. Refletindo sobre essa questão, além do desafio em aprender a ensinar, vê-se também o desafio em ensinar em um contexto novo.

É importante, além disso, destacar o acúmulo de função do profissional de saúde enquanto preceptor. Salvo raras exceções, a grande maioria desses profissionais exercem outras atividades. São algumas dessas: assistência a usuários, preceptoria de estudantes de graduação, pesquisador ou colaborador 
em projetos de pesquisas e gestor em unidades de saúde. Dentre essas, a maior é a assistência a usuários, com média de $89,8 \%{ }^{10}$.

Apesar de contar com módulos para a descrição desses itens, espera-se que com o uso das tecnologias educacionais apoiadas pelas TDICs e das metodologias ativas no decorrer de todo o curso, o aperfeiçoando possua subsídios não apenas para uma melhor compreensão, mas também para o bom uso desses recursos. É considerável destacar que a maioria dos profissionais não conhecia esses recursos.

A formação foi dividida em 4 módulos. A temática do primeiro módulo "Residências em saúde no SUS" contou com carga horária de 20 horas, sendo dessas 8 horas em EaD. Teve como ementa "O que são Residências em Saúde; Princípios e diretrizes do Sistema Único de Saúde e Política de Educação Permanente em Saúde". As metodologias de ensino foram sala de aula invertida, discussões expositivas e fóruns via plataforma Canvas.

O segundo módulo, intitulado "Recursos pedagógicos" contou com 24 horas de carga horária, sendo 6 horas em EaD. Utilizou como ementa as temáticas "Metodologias ativas; Educação popular em saúde; Currículo baseado em competências e Tecnologias educacionais e digitais". As metodologias de ensino foram sala de aula invertida, oficina de vivência prática de tecnologias educacionais digitais e fóruns via plataforma Canvas.

O terceiro módulo foi "Preceptorias em Saúde", contando com uma carga horária de 16 horas, sendo dessas 4 em EaD. Aqui foram apresentados a parte operacional da preceptoria, com as temáticas "noções básicas de gestão de programas de residência; como dar e receber feedbacks; planejamento didático, andragogia e sala de aula invertida". Teve como metodologia "Aprendizagem Baseada em Problemas (PBL); exposição de vídeos pelo YouTube; role-playing e fóruns via plataforma Canvas".

No $4^{\circ}$ e último módulo, os preceptores construíram um Trabalho de Conclusão de Curso, com projetos de intervenção acerca da atuação em preceptoria. Aqui foram 40 horas, sendo 8 horas presenciais, onde foram abordadas as temáticas "Metodologia do Trabalho Científico", "Ética em Pesquisa" e "Como elaborar um projeto aplicativo". O restante da carga horária foi destinado à construção do TCC e discussões de orientação online.

Ao final, foram apresentados painéis digitais para compartilhamento dos resultados obtidos, incluindo como categorias a reformulação de matriz curricular, relações interpessoais e otimização do tempo em ensino e serviço. 
Dentro dessas categorias foram elaborados projetos de intervenção, sendo em alguns casos já apresentados os resultados obtidos. Esse aspecto contemplou uma das principais propostas do curso, promover a reflexão acerca da resolução de conflitos, estimulando o senso crítico e a identificação e resolutividade de nós críticos.

As tecnologias podem ser divididas em duras, sendo tecnologia material como equipamentos, computadores, etc.; durasleves, constituindo saberes estruturados, teorias, protocolos e metodologias. São a integração do conhecimento técnico da tecnologia dura com a subjetividade da tecnologia leve; e a tecnologia leve, correspondendo a subjetividade, vínculo e relações ${ }^{11 .}$

No campo educacional, é importante a interação entre todas essas tecnologias, fugindo da percepção de que apenas a dura é de fato tecnologia. O aprendizado se dá através do vínculo, das trocas e da interação entre professor-aluno e alunoaluno, assim como o empoderamento do aluno enquanto autor do seu aprendizado. Assim, os recursos digitais são um meio para se chegar no objetivo final, não o objetivo em si.

Educação e tecnologia atualmente são indissociáveis. Com o avanço do crescimento tecnológico e a integração das redes de comunicação, as tecnologias digitais nos cercam o tempo inteiro.
Atualmente as TVs, tão usadas antigamente para a propagação da educação a distância, hoje são conectadas a internet, os smartphones são inseparáveis na nossa vida. Assim, é fundamental pensar no uso dessas ferramentas a nosso favor, tornando as aulas mais atrativas e facilitando $o$ aprendizado $^{12}$.

Levando em conta o uso de tecnologias digitais no cotidiano, percebemos o quanto nossa forma de consumir, viver, comunicar e existir no mundo está atrelada ao seu uso. Por exemplo, cresce o número de pessoas que dedicam sua carreira profissional para 0 uso da influência digital, como blogueiros e youtubers. No entanto, a educação não tem acompanhado com a mesma rapidez as tecnologias digitais. Apesar dos avanços, a educação tradicional ainda é a principal referência de ensino que possuímos, sendo essas tecnologias secundárias ${ }^{13}$.

O uso das metodologias ativas é um desafio, pois pede que 0 aluno tome a frente no seu processo de ensinoaprendizagem. Ao romper com o modelo já conhecido, surge o desafio de tornar o aprendizado atrativo, já que o mesmo nem sempre favorece o envolvimento dos alunos. Além disso, é um desafio fugir da educação tradicional buscando usar criatividade para compensar a perda do 
"poder" por parte de quem supostamente domina o saber.

Algumas metodologias ativas foram utilizadas nesse relato, como a sala de aula invertida, onde os conteúdos, a parte teórica, são disponibilizados para serem estudados de forma online, contando com a sala de aula como espaço para discussão, debates e mútuo aprendizado; a Aprendizagem Baseada em Problemas (PBL), onde ao invés de ter um conteúdo teórico pré-estabelecido são elencados problemas a serem solucionados através de análise e elaboração de hipóteses de resolução, para a partir daí iniciar os estudos e desenvolver a resolutividade; de modo semelhante, a Aprendizagem Baseada em Projetos se propõe a facilitar o aprendizado a partir da problematização da realidade ${ }^{12}$. Pensando no contexto da saúde, essas estratégias seriam fundamentais não apenas para a absorção de conteúdos, mas também para o desenvolvimento de habilidades e a aplicação prática.

Complementando, para o uso convergente das metodologias ativas com os recursos digitais interativos é fundamental utilizar-se de criatividade e ter disposição para seu emprego adequado. Como citado anteriormente, é mais cômodo o uso das práticas tradicionais de ensino, preparando o conteúdo que o professor julga necessário e depositando esse conhecimento no aluno.
Das 24 vagas oferecidas, apenas 15 foram preenchidas e destes, apenas 8 preceptores concluíram o curso. No entanto, é nítida a mudança na condução da prática docente daqueles que concluíram, sendo integradas na prática dos mesmos as metodologias as quais foram apresentados enquanto alunos do curso. A condução dos métodos avaliativos, o planejamento dos estudos das linhas de cuidado, os momentos de estudos teóricos, o conhecimento do próprio funcionamento da residência e o alinhamento das ações com o Projeto Político-Pedagógico são exemplos de mudanças, além da percepção do seu papel enquanto docente.

Levando em conta o fluxo intenso e exaustivo de trabalho no ambiente hospitalar, as aulas foram planejadas para ocorrerem aos sábados, quinzenalmente, já que pelo intenso fluxo de usuários nos dias considerados úteis não seria possível a participação efetiva desses preceptores.

No entanto, esse também foi um motivo relatado pelo índice de evasão, já que devido ao cansaço acumulado não havia disposição para assumir esse compromisso aos fins de semana. Importante ressaltar que a participação na formação não foi compulsória. 


\section{Conclusão}

Conduzir um programa de residências é extremamente desafiador, traz consigo a responsabilidade de cuidar da formação dos profissionais que estarão inseridos no Sistema Único de Saúde, constituindo esses responsáveis pelo cuidado ético, técnico e humano ao usuário.

A residência é um período intenso e exaustivo para todos os envolvidos e é possível atribuir essa problemática a insuficiência de clareza e consenso no âmbito nacional sobre o que de fato deve reger os programas, além disso, pode ser pontuada também a insuficiente capacitação dos preceptores, atores importantíssimos no processo de ensinoaprendizagem e responsáveis por $80 \%$ da formação, e a elevada carga horária, tornando todas as vivências mais aguçadas.

Assim, esse relato se propõe a preencher uma lacuna no processo formativo, sendo o primeiro passo para um programa de educação continuada para preceptores do SUS.

Penso que trazer o uso dessas tecnologias é se apropriar dos recursos disponíveis, facilitando o aprendizado e emancipação do educando, sendo assim também um estimulador da autonomia, possibilitando que esse, aplicado aos usuários, possa gerar um ciclo de cuidado.
Percebemos aqui a influência de uma eficiente formação docente na condução de uma residência. Assim, podemos gerar um ciclo de cuidado, já que a condução eficaz de um programa de residência pode estar ligada aos recursos pedagógicos dos quais o preceptor dispõe. Desse modo, o usuário seria o maior beneficiado, já que esse cuidado chegaria a ele de forma mais eficaz e com profissionais de saúde bem preparados.

Através das discussões levantadas no planejamento e na execução dessa formação, foi perceptível a necessidade de momentos de encontros mensais, favorecendo espaços de discussão, apoio e compartilhamento de tomadas de decisões.

No entanto, apesar dos ganhos positivos, essa reflexão pode trazer outras inquietações, como investigar quais os motivos da falta de formação docente desses preceptores, assim como uma avaliação eficaz dos resultados a médio e longo prazo dessa formação.

\section{Referências}

1 Organização Mundial de Saúde. Constituição da Organização Mundial de Saúde (OMS/WHO). 1946

2 Ministério da Saúde (BR). Portaria n.198. Institui a Política Nacional de Educação Permanente em Saúde como estratégia do Sistema Único de Saúde para a formação e o desenvolvimento de trabalhadores para o setor e dá outras providências. Brasília, DF. 2004 
3 Ceccim RB. Educação Permanente em Saúde: descentralização e disseminação de capacidade pedagógica na saúde. Ciênc. saúde coletiva. 2005;10(4):975-986.

4. Amancio Filho A. Dilemas e desafios da formação profissional em saúde. Interface (Botucatu), 2004;8(15):375-380.

5 Dallegrave D; Ceccim RB. Encontros de aprendizagem e projetos pedagógicos singulares nas residências em

Saúde. Interface (Botucatu).

2018;22(66):877-887.

6 Nascimento DDG; Oliveira MAC. A política de formação de profissionais de saúde para o SUS: considerações sobre a residência multiprofissional em saúde da família. Rev. Mineira de Enfermagem, 2006;10(4):435-439.

7 Neta AA; Alves MSCF. A comunidade como local de protagonismo na integração ensino-serviço e atuação

multiprofissional. Trab. educ. saúde.

2016;14(1):221-235.

8 Pretto N de L.; Riccio NCR. A formação continuada de professores universitários e as tecnologias digitais. Educar.

2010;26(37):153-169.

9 Afonso DH; Silveira LMC. Os desafios na formação de futuros preceptores no contexto de reorientação da educação médica. Revista Hospital Universitário Pedro Ernesto. 2012;11 (Supl. 1):82-86. 10 Aguiar AC (org.). Preceptoria em Programas de Residência: ensino, pesquisa e gestão. Rio de Janeiro: CEPESC/IMS/UERJ; 2017.

11 Coelho MO; Jorge MSB. Tecnologia das relações como dispositivo do atendimento humanizado na atenção básica à saúde na perspectiva do acesso, do acolhimento e do vínculo. Ciênc. saúde coletiva. 2009;14 (Supl.1):1523-1531. 12 Fofonca E (Coord.); Brito G.S; Estevam M; Camas NPV (Orgs.). Metodologias pedagógicas inovadoras: contextos da educação básica e da educação superior. Curitiba: Editora IFPR; 2018.

13 Valente J. A comunicação e a educação baseada no uso de tecnologias digitais de informação e comunicação. Revista UNIFESTO. 2014;1(1):141-166. 


\section{Como citar este artigo}

Rodrigues EMS; Silva KKD da. Tecnologias educacionais digitais na formação de preceptores para residências multiprofissionais no SUS. Revista de Saúde Digital e Tecnologias Educacionais. [online], volume 5, n. 1. Editor responsável: Luiz Roberto de Oliveira. Fortaleza, mês e ano, p. 112-123. Disponível em: http://periodicos.ufc.br/resdite/index. Acesso em "dia/mês/ano".

Data de recebimento do artigo: 16/10/2019

Data de aprovação do artigo: 25/01/2020

Data de publicação: 17/04/2020 